\title{
Theorising terminology development: Frames from language acquisition and the philosophy of science
}

\author{
Bassey Antia and Bem Ianna
}

\begin{abstract}
The manner in which our conceptualisation and practice of terminology development can be informed by processes of knowledge change in child language development and a paradigm shift in disciplines, has been relatively underexplored. As a result, insights into what appears to be fundamental processes of knowledge change have not been employed to reflect on terminology development, its dynamics, requirements and relationship to related fields. In this article, frames of knowledge change in child language development and the philosophy of science are used to examine terminology development as knowledge growth that is signalled lexico-semantically through a range of transformations: addition, deletion, redefinition and reorganisation. The analysis is shown to have implications for work procedures, expertise types, critique, and for the relationships between terminology development and translating.
\end{abstract}

\section{Introduction}

Terms are items of designation 'characterised by special reference within a discipline', and the totality of terms of a discipline form that discipline's terminology (Sager 1990, 19). Terminology development refers to a process of functionally extending, especially, the lexical semantics of a language into new domains. The purpose is often to facilitate communication of specialised knowledge units or knowledge structures that were either previously nonexistent in the conceptual universe of speakers of a certain language, or unattested in a form considered adequate for new demands of communication (Antia 2000, 33). Although terminology resources (e.g. databases, print dictionaries) can be intended for audiences (e.g. in teaching and learning, mass media, translation, authoring, and so on) with different needs (Arntz, Picht and Schmitz 2014, 298; Kühn 1989), terminology development in language planning contexts of the developing world is fundamentally linked to the management of knowledge growth or change. It therefore requires attention to knowledge structures.

Virtually every attempt at modelling language planning, from Haugen's classical outline (Haugen 1966) through the dozen models reviewed in Antia (2000) to Hornberger's (2006) integrative model, would typically have a stage that deals with terminology development. In the language planning literature and in the experience of many language 
communities, the nature of preoccupation with terminology development is such that the caution sounded by the late, regretted Joshua Fishman many years ago, is arguably still relevant today. Fishman $(1983,108)$ wrote as follows:

The tendency to view "corpus planning" as nothing special, as just one more technical skill that a linguist should be able to pull out of his bag of tricks, is triply mistaken. It reveals a misunderstanding of lexicons per se, of corpus planning as a whole, and of the societal nexus of language planning more generally.

Fishman argued that terminology development was more than a 'simple, technical, linguistic exercise'; that lexicons were not 'interchangeable, dry and dreary "nuts" and "bolts"; nor 'endless laundry lists, without rhyme and reason, without order or pattern, without systematic links to each other and to all other facets of language' (Fishman 1983, 108). Fishman's interest lay ultimately in underscoring the societal auspices within which corpus planning is carried out.

Fishman's caution can be reappropriated and embedded within other frameworks to understand some of the knowledge dynamics possibly inherent in the process through which a language is made to transition from, say, a rather rudimentary stock of vocabulary in a given subject field to a medium that is adequate to support new communication demands. Pausing to reflect on how knowledge change in terminology development is lexico-semantically indexed may have implications or a range of relevant methodological questions. Although the perception that terminology is an intractable obstacle to the use of African languages in high- function domains has been dismissed as scarecrow tactics employed to justify inertia or the status quo (Bamgbose 2000, 88; Webb 2004, 154), it remains pervasive and can perhaps be addressed to some extent by a closer examination of how a language progresses to become a medium for expressing previously unattested knowledge units or structures. Also, given the sometimes negative views of decisions taken in terminology development, a knowledge change perspective potentially provides the canvas for developing arguments that are anchored in the peculiarities of the subject field to rationalise decision-making (Antia and Clas 2003, 48).

In this article, insights from two unlikely sources, viz. child language acquisition (specifically, vocabulary acquisition) and the philosophy of science, which seem to flesh out Fishman's points about the lexicon, are employed to examine and to frame some of the knowledge change issues that are possibly inherent to the process through which the functional range of a language is terminologically extended. Child language acquisition research offers descriptions of differences between child and adult speech, and how the former progresses to the latter (Allot 2005; Boysson- Buddies 2001; Crystal 1987; Oates and Grayson 2004; Saxton 2010). With its interest in how science works, the philosophy of science similarly describes different states of knowledge in a field, and shows how a later stage evolves or revolves from an earlier state (Kuhn 1996; Thagard 1992). Based on an analysis of insights 
from these two frameworks, we review accounts of terminology development in the literature to answer the following questions:

1. Is terminology development (as knowledge change) mainly an accretive process, involving essentially the adding of new terms to the vocabulary stock of a language?

2. What other processes of knowledge change are evident and significant in terminology development?

We view accretion here as growth of the vocabulary through neologisms or the creation of new lexical entities. Following Sager $(1997,38)$, we see two kinds of neologisms: borrowing from other languages, and totally new forms previously not attested in a language. In English, examples of the latter include gas, paraffin and byte.

In subsequent sections, the following issues are addressed in turn: knowledge change in child language acquisition, knowledge change in the philosophy of science, a synthesis of insights from both fields, a re-reading of accounts of terminology development from the standpoint of both of these fields, and a discussion as well as the implications of the analysis.

\section{Knowledge change in child language acquisition}

It is generally agreed that language development does not begin suddenly. Children do understand and respond in non-verbal ways to the utterances of others long before they begin to produce holophrases, and then move to other stages as their knowledge increases (Ambridge and Lieren 2011; Atkinson 1982; Lust 2006). Though the early scholars to carry out studies on early language acquisition had different theories (e.g. Skinner's behaviourism and Chomsky's innatism), there is some consensus on the sequence of language acquisition: pre-speech stage; one-word stage; two-word stage; telegraphic stage; and multi-word stage (Blom and Unsworth 2010; Lenneberg 1967; Montgomery 2008; Pinker 1994; Vygotsky 1962). While there is a great deal of variation in accounts of the age at which children reach a given milestone, similar patterns of development have been observed in many children (Allot 2005; Reich 1986).

In the area of vocabulary development, researchers have pointed out that children's attachment of meanings to new words they have to learn is guided by implicit biases or expectations that lead them to favour some possible meanings over others (Devescovi, Casselli, Morchione, Pasqualetti, Relly and Bates 2005; Dromi 1996; Sonaiya 1991). These expectations reduce the ambiguity inherent in the word learning scenario by narrowing the range of possible meanings a child considers when ascribing meaning to a new word. Sonaiya (1991) has described aspects of this process as continuous lexical disambiguation, by which she means a continuous refining of meaning and readjustment of boundaries between lexical items that have already been acquired and subsequent items that are encountered (and semantically related to previously acquired items). Fishman, it would be recalled, had cautioned that the lexicon was not some 'endless laundry lists, without rhyme and reason, without order or pattern, without systematic links to each other and to all 
other facets of language' (Fishman 1983, 108). It is, therefore, not surprising that acquiring vocabulary similarly involves decisions based on systematic links.

Sonaiya illustrates her Continuous Lexical Disambiguation Model with the example of vocabulary development in a child who initially refers to all four-legged animals as 'dog' but later acquires the distinctions that exist between a dog and other four-legged animals. As this distinction is acquired, boundaries are set up and continuously readjusted, rearranged or reorganised to reflect the current stage of the knowledge of the child (Sonaiya 1991, 281).

The key point here for this article is this: as knowledge increases, changes characterised by deletion, addition, coalescence, and so on occur in the learner's structural organisation of the target language vocabulary. The manner in which this modelling of knowledge change applies to terminology development is of interest to this article.

In his description of the evolution of child language, Reich (1986) identifies seven categories in children's speech prior to their attaining adult-like speech. The categories are underextension (when the range of referents of a word for a child is narrower than for an adult); overextension (the range of meaning is greater for the child than for an adult); overlap (when the range of the referents is overextended in some areas and underextended in others); mismatch (when the child's meaning for a word does not overlap that of the adult); identity (when the range of the child's word is the same as that of the adult); idiomorphs (when a child uses words that are not part of the vocabulary of the adult). Reich's last category is termed words that have not been learned by the child, which we refer to as 'potential' in Figure 1. Figure 1 is an attempt at graphically representing these seven categories, which have been subsumed under four broad categories, namely, nonequivalents (idiomorphs, mismatches), near equivalents (overextensions, underextensions, and overlaps), identity (identity) and potential (yet to be learned). 


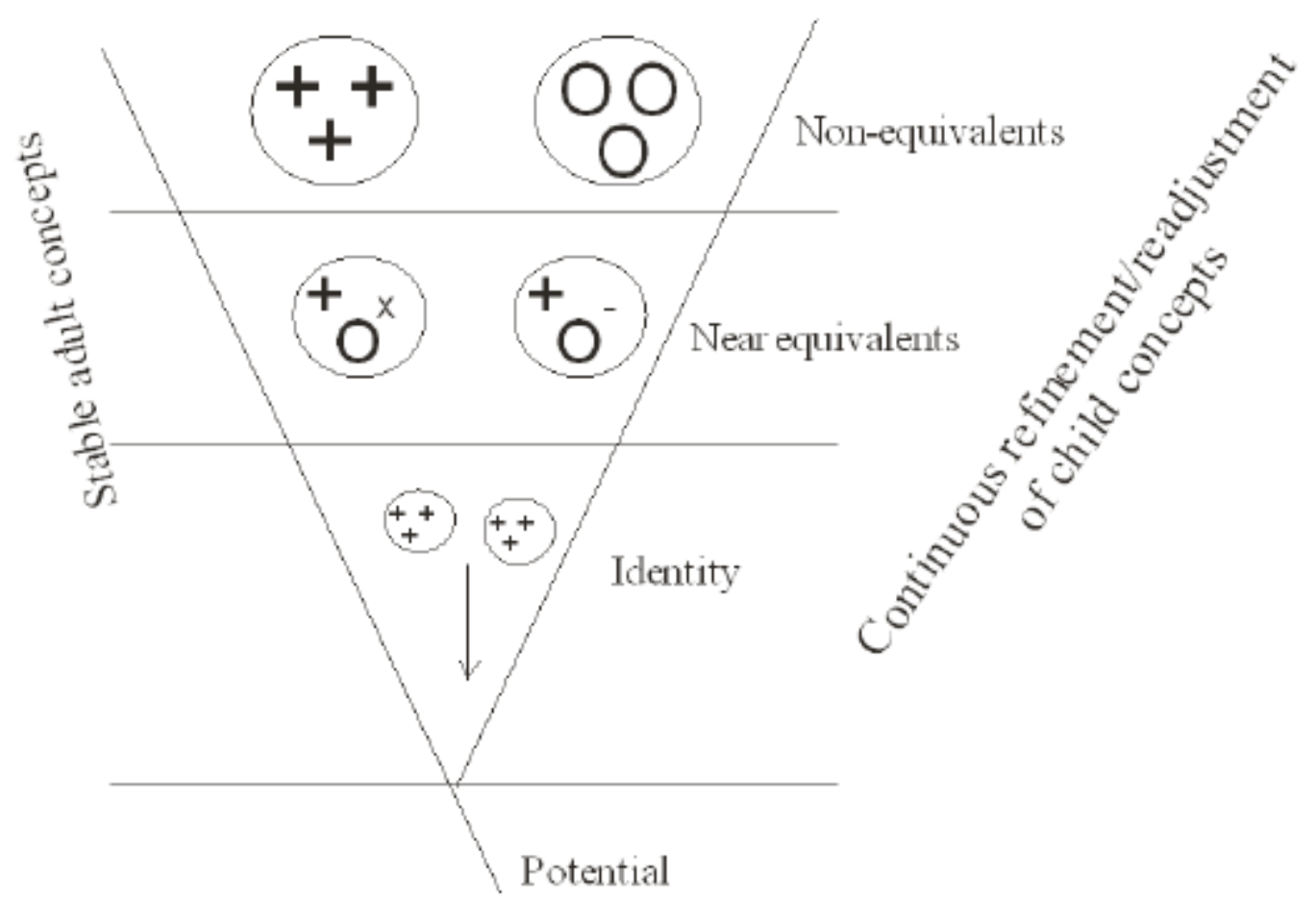

Figure 1: An illustration of child language/conceptual development

For the argument to be made about terminology development in this article, the important point to note from the above account is that the process (from, say, idiomorphs through mismatches and overextension to identity) through which a child's vocabulary knowledge evolves to become adult-like is not only indexed by the acquisition of new words. For instance, with overextension, which is a category of near-equivalence, a set of words is repeatedly called to do different kinds of meaning duty. Dromi's example of a child between age 12 and 23 months is instructive (Dromi 1996). Within this period, of the 340 words produced by the child, 300 (representing 88.2\%) had been acquired previously. Only 40 (representing $11.8 \%$ ) were the new words acquired within this age bracket.

In sum, this and other accounts of vocabulary growth (e.g. Bloom 1993) show that while there are spurts or moments when children actually add new words to their lexical repertoire, at other times their vocabulary development is indexed more by meaning refinements or reorganisation on the basis of already known words. In the next section, we will examine if comparable categories of knowledge change are employed in accounts in the philosophy of science, then proceed to use insights from both frameworks to examine accounts of terminology development.

\section{Knowledge change in the philosophy of science}

According to The New Webster's Dictionary, a revolution can be said to be a dramatic change in ideas or practices, or any fundamental change or reversal of conditions. Applied to disciplinary knowledge, revolutions are 'those non- cumulative developmental episodes 
in which an older paradigm is replaced in whole or in part by an incompatible new one' (Kuhn 1996, 92). Kuhn further notes that 'during revolutions scientists see new and different things when looking with familiar instruments where they have looked before'. Evolution, on the other hand, has its origin in biology where it was used to describe development from earlier forms, that is, the process by which all species develop from earlier forms of life (Budin 1996, 27). In contemporary usage, the term is used to refer to the gradual development or change of conceptualisation. The common point in the two concepts is that both evolution and revolution can be construed ultimately as instances of knowledge change.

The specific processes through which this change takes place have been of interest to scholars. In the Archaeology of Knowledge, in the appositely titled chapter, 'Formation of Concepts,' Foucault (1972) notes that in the $17^{\text {th }}$ and $18^{\text {th }}$ centuries, Natural History assigned new definitions to pre-existing terms like 'genus' or 'character', thus forming new concepts; it introduced new concepts like 'natural classification' and 'mammal'; most importantly, however, it provided a system for interpreting and re-interpreting relations among existing and new terms and concepts (Foucault 1972, 57). Foucault makes the point clearly that the evolution of Natural History was not an accretive, 'stone-by-stone construction of an edifice' (Foucault 1972, 56).

Thagard $(1992,3)$ sees scientific revolutions as taking place when 'science undergoes dramatic conceptual changes'; in other words, 'when whole systems of concepts and laws are replaced by new ones'. As with child acquisition of vocabulary, conceptual revolutions involve major additions or deletions of beliefs, the reorganisation of concepts, and/or the redefinition of conceptual hierarchies. This is illustrated in the tree diagrams in Figures 2 and 3. Figure 2 provides Ptolemy's conceptualisation of the universe. 


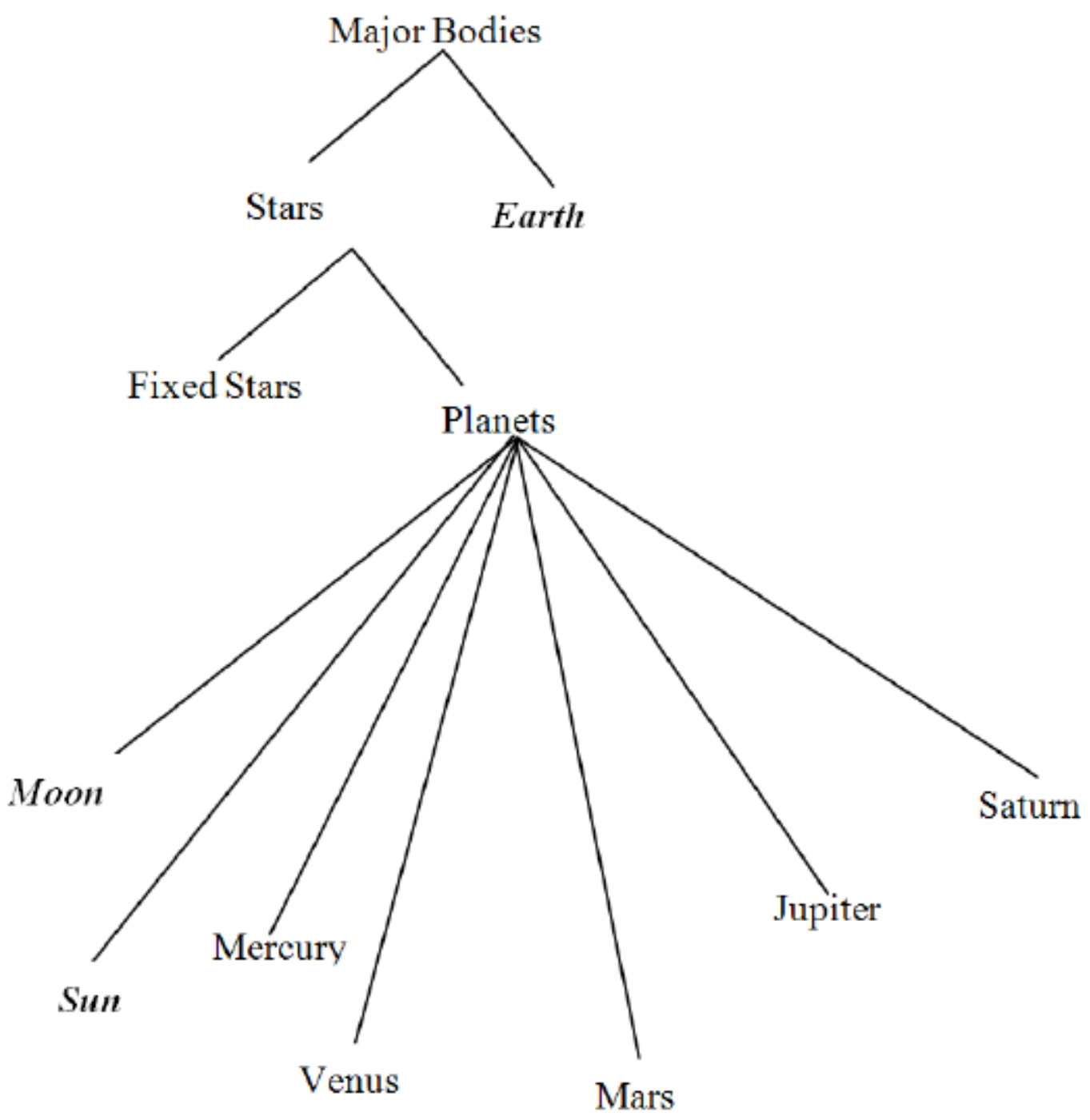

Figure 2: Conceptual system of Ptolemy (adapted from Thagard 1992, 194)

It is interesting to compare Ptolemy's conceptual system in Figure 2 with that of Copernicus in Figure 3. 


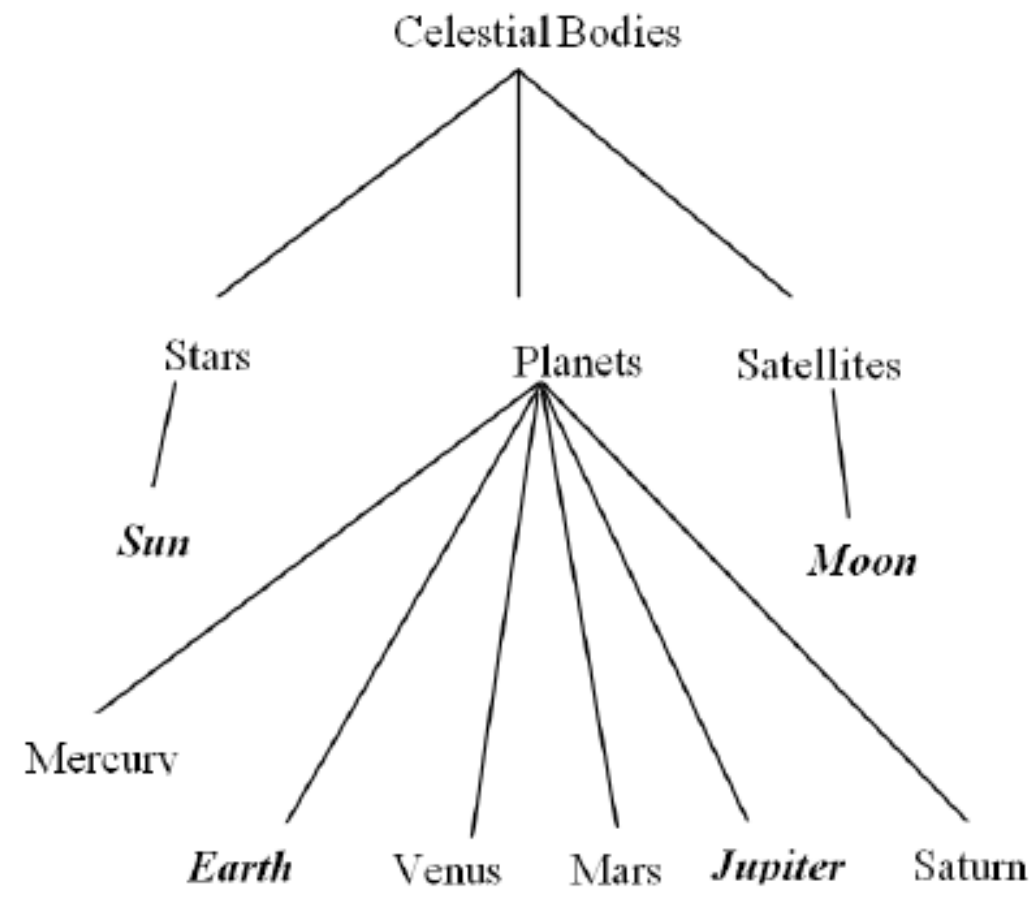

Figure 3: Copernicus' conceptual systems of modern astronomy (adapted from Thagard 1992, 195)

As seen in Figures 2 and 3, there are changes in the accounts provided by Ptolemy and Copernicus, even when the same terms are used. For example, in the Ptolemy model (Figure 2), the earth is a unique kind, and the sun and the moon are counted as planets. But in the Copernicus model (Figure 3), the earth has moved to the rank of planets, and the moon as a type of satellite, while the sun has been reclassified as a type of star. Thagard's analysis of conceptual revolutions here shows that they involve:

- Major additions or deletions of beliefs, e.g. earth has been added to the class of planets in Copernicus' conceptual system, and moon and stars have been deleted from there.

- The reorganisation of concepts, e.g. the earth jumps from its own branch in the kindtree to reside under planet, while the sun and the moon jump from the class of planets to other classifications.

- Redefinition of conceptual hierarchies, e.g. Copernicus' definition of the earth becomes different from that of Ptolemy - it now has planet as definitional genus proximum. In the same way, the sun in Copernicus' model acquires star as definitional genus proximum, and the moon acquires (natural) satellite of the earth as genus proximum.

These processes are as valid for conceptual revolutions as they are for evolutions. Kuhn (1996, 172) provides a relevant account of the latter. Darwin's evolutionary theory, for example, was part of a very different conceptual framework from the creationist one. The 
theory holds that complex creatures evolve naturally from more simplistic ancestors. In Darwinian biological evolution, the concept of 'special creation' was deleted and replaced by 'adaptation' and 'natural selection'; 'man' which was previously taken to be a different creature became reclassified as a kind of animal (reorganisation). Before Darwin, 'kind' was defined in terms of similarity, but he redefined it in terms of descent.

\section{Synthesis: child language acquisition and scientific knowledge (r)evolution}

It can be seen that knowledge change in the two processes under review (child language acquisition and philosophy of science) have comparable characteristics. In both accounts, it is clear that growth or change in knowledge is indexed by all or several of the following: disappearance of old words, appearance of new words, changes in the semantics of existing words (intension and extension), and structural reorganisation of the conceptual space. Processes of knowledge change can, following Thagard (1992), be represented as in Figure 4.

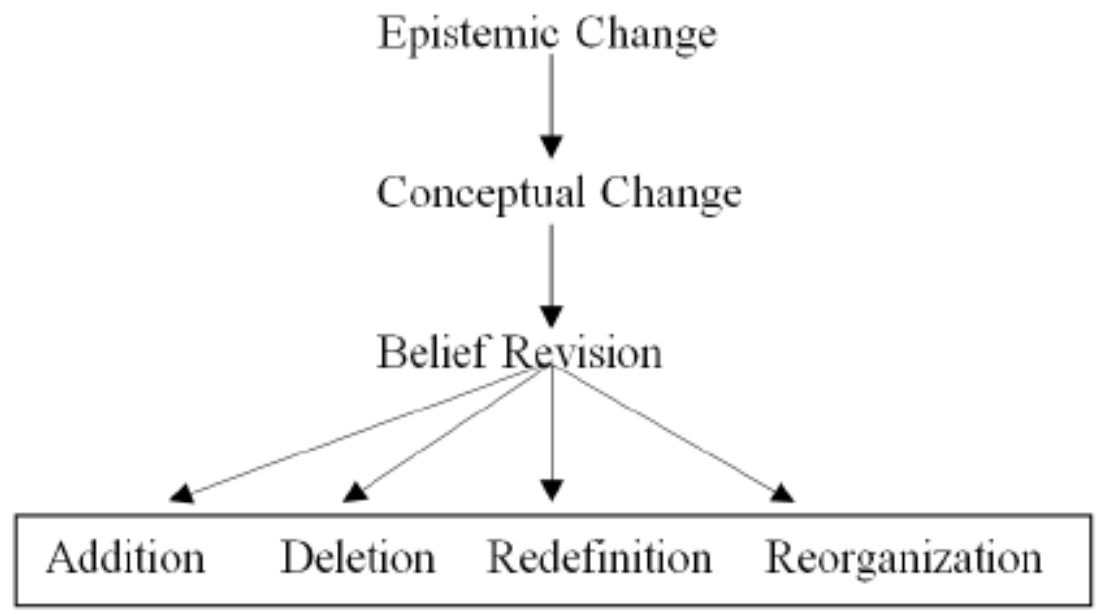

Figure 4: An illustration of conceptual change (Thagard 1992, 37)

Of particular interest in Figure 4 are the four manifestations of belief revision. Table 1 illustrates these manifestations or categories of change, using data from child language acquisition and philosophy of science. 
Table 1: Exemplifications of categories of knowledge change in child language acquisition and philosophy of science

\begin{tabular}{|l|l|l|}
\hline Changes & $\begin{array}{l}\text { Examples from child language } \\
\text { acquisition }\end{array}$ & $\begin{array}{l}\text { Examples from philosophy of } \\
\text { science }\end{array}$ \\
\hline Addition & $\begin{array}{l}\text { New words are added as the child } \\
\text { develops, e.g. acquiring daddy } \\
\text { after mama has been acquired. }\end{array}$ & $\begin{array}{l}\text { Darwin added concepts like } \\
\text { 'natural selection' and 'adaptation' } \\
\text { to evolutionary biology. }\end{array}$ \\
\hline Deletion & $\begin{array}{l}\text { For instance, children drop their } \\
\text { idiomorphs and replace them with } \\
\text { normal words of the language, } \\
\text { e.g. a child may drop chefchef for } \\
\text { 'shaving powder.' }\end{array}$ & $\begin{array}{l}\text { In Darwinian biological evolution, } \\
\text { the concept of 'special creation' } \\
\text { was replaced by 'adaptation' and } \\
\text { 'natural selection'. }\end{array}$ \\
\hline Redefinition & $\begin{array}{l}\text { Uncle may, initially, be defined in } \\
\text { terms of any mature person. Over } \\
\text { time, with increased knowledge, } \\
\text { it becomes redefined in terms of } \\
\text { family relationship. }\end{array}$ & $\begin{array}{l}\text { In the pre-Darwinian era, kind was } \\
\text { defined in terms of similarity, but } \\
\text { Darwin redefined it in terms of } \\
\text { descent. }\end{array}$ \\
\hline Reorganisation & $\begin{array}{l}\text { All forms of liquid may initially } \\
\text { be referred to as water by the } \\
\text { child, but with time they become } \\
\text { differentiated into juice, water, and } \\
\text { so on. }\end{array}$ & $\begin{array}{l}\text { Before Darwin, 'man' which was } \\
\text { previously taken to be a different } \\
\text { creature became reclassified as a } \\
\text { kind of animal. }\end{array}$ \\
\hline
\end{tabular}

In the next section, we use the frames for accounting for knowledge change in both of these fields to re-read accounts of terminology development in order to answer the two questions posed at the beginning. Because detailed analyses of decision-making in terminology development projects are often not available (beyond what can be inferred from termformation strategies), the re-reading is based on an admittedly small dataset, and especially on a major undertaking with which the first author was involved.

\section{Accounting for terminology development as knowledge change: frames from child language acquisition and philosophy of science}

In seeking to verify how applicable knowledge change frames in child language acquisition and philosophy of science apply to terminology development, we do not assert that language is a child or a scholarly field; it is also not our intention to overstate symmetries. Nonetheless, the above framework provides a basis for reflecting on terminology development in a manner that sheds light on a number of methodological and attitudinal concerns. Let us now turn to the first research question on the significance of accretion in terminology development.

\subsection{Terminology development and accretion}

We had earlier outlined our view of accretion as growth of the vocabulary through neologisms of two kinds (borrowing from other languages and totally new creations). The question as to whether terminology development is all or substantially about adding 
neologisms to a language is especially relevant in African contexts, where the absence of terminology in indigenous languages is all too often cited as the reason why these languages are inappropriate as media of instruction, as vehicles for production or popularisation of scientific knowledge, or as means of running a modern bureaucracy. Perhaps underlying these claims is the assumption that terminology development is all about neologisms, an intimidating or problematic task, compared to, say, the reinterpretation of existing forms.

In work on terminology in African language planning contexts, there is some evidence that accretion as understood above in fact plays a relatively minor role. In keywords extracted by Gauton, Taljard and De Schryver (2003, 83) from a particular corpus of parallel texts in all of South Africa's official languages, we find that nativised and non-nativised loans from English ranged from 6 per cent (in the Afrikaans corpus) to 23 per cent (in the Xitsonga corpus), with the mean being 12 per cent. Thus, conversely, a mean of 88 per cent of the terms were obtained through language-internal resources. In the 187-entry term-base on aspects of legislative procedure in the Efik language (reported in Antia 2000), 17 per cent of the terms were words that existed previously with appropriate legislative meanings; 81 per cent were obtained through processes of reinterpreting existing meanings or combining existing words. In terms of accretion as complete novelty, only 2 per cent of the terms had not existed previously in some form or the other in Efik. Mabasa (2006) studies two sets of health-related terminology in the Xitsonga language developed, respectively, by a relevant department of the South African government and health professionals. In terms of complete novelty (which in Mabasa's case is captured by items arrived at via transliteration and direct loan), 15 per cent of the terms on the government department's glossary and 7.8 per cent on the health professionals' list were novel (Mabasa 2006, 27).

A qualitative, but no less instructive account, is provided by Maiga (1991) of how a team involved in a botany course was to create horticultural terminology in the Bambara language. Most course participants were convinced that beyond equivalents for a few terms like root, stem, flower, leaf, the target language had no botanical terms. Members of the team could already see themselves battling with petals, corolla, ovary, and so on. On visiting Bambara villages, however, the team realised the villagers already had terms for petals (feere kala), corolla (julakôrôbô), stamen (ionbôjonbô), pistil (denkala), and for ovary (denso).

These sets of examples make the point that terminology development is not always, nor even significantly, an accretive exercise of adding new terms in the sense of previously nonexistent material in a given language. In mooring these findings to the models from child acquisition research and the philosophy of science, we see that while (terminology development to effect) knowledge change does get indexed by the addition of new lexical material, thus accretion, it is frequently the case that change will be indexed by other strategies. Recall, for instance, Dromi's example of how a child communicates between age 12 and 23 months. Only 11.8 per cent of the words used by the child were acquired in this 
age bracket, the remaining 88.2 per cent having been acquired previously. Overextension and overlap would suggest that a set of words presumably had to do duty repeatedly for different kinds of adult meanings.

Let us now turn to our second research question. We had seen in Table 1 that, apart from accretion, knowledge change in the two selected frameworks was also indexed by redefinition, deletion and reorganisation. Consequently, in responding to the second research question, we seek evidence from the literature under the three headings of redefinition (or semantic extension), deletion and reorganisation.

\subsection{Terminology development and redefinitions (or semantic extension)}

Redefining or extending the meaning of existing words, to make them appropriate for new concepts, is a widespread practice in terminology development. It underscores the need for terminology resources to have definitions that draw attention to the new, specialised meanings.

A quantitative perspective to the significance of semantic extension can be gleaned in the claim in Antia (2000, 212): some 80 per cent of the one-word terms were arrived at through extending the meaning of existing words to designate new concepts. Thus, ediomi was extended from the general language meaning of 'deal' or 'pact' to the legislative meaning of 'resolution'; nneme from 'discussion' to (noun) 'debate'. In the study by Gauton et al. (2003, 87), a quantification of strategies for isiZulu and Sepedi shows that 40 per cent of the terms for the former and 45 per cent for the latter were arrived at through various forms of semantic extension (semantic specialisation, use of a narrower word, use of a more general word - all reminiscent of Reich's categories in child language acquisition). In Mabasa's study, about 80 per cent of the terms in the government department's glossary were arrived at through internal strategies (using a more general word, paraphrase, compounding, semantic extension), while the figure on the health professionals' list was, at 92 per cent, even higher (Mabasa 2006, 27).

These statistics build on the earlier set on accretion to provide reassurance that the development of terminology calls more for creativity in reusing available resources creativity based on analysing the characteristics of concepts to be designated - than the presumably more challenging generation of completely novel resources.

As was suggested earlier, semantic extension makes definitions indispensable. One consequence of the neglect of definitions in terminology resources is reported in Antia (2000, 60). In the Hausa language glossary evaluated, the English legislative term 'motion' had been given the equivalent batu, which in the general language designates 'talk'. So, in other words, 'talk' had been extended to (legislative) 'motion'. In a think-aloud translation experiment, participants did not use this equivalent at the point where the text they were translating required an equivalent for 'motion'. Participants felt batu was wrong. Obviously, they needed a definition that would have justified this new specialised 
meaning for a word with a known or general language meaning; in other words, a definition that would have declared the intended relationship between batu and 'motion'. Such a definition might have started as follows: 'In the legislative field, batu is the term for English 'motion' and it designates...'.

\subsection{Deletions (as a result of mismatches) in terminology development}

Criticisms are sometimes directed at items in terminology resources because words in the general language assumed to be useful in a specialised field, were dropped. Cases of mismatch and deletion between a language's current and targeted state of domain-relevant knowledge can be seen in the two examples below. In the legislative terminology described by Antia (2000, 205), the panel had to provide an Efik language term for the English 'to vote'. It initially seemed that the pre-existing word, mek (to choose, elect), would be the obvious choice. In the traditional conceptual universe of the Efiks of southern Nigeria, mek is a form of indicating preference at elections or at meetings, enacted either by thumb-printing or by a show of hands.

However, a challenge arose when the panel developing the terminology realised that, in the reference concept system, voting was not only about electing but also indicating preference for positions. There was also the point about there being several types of voting (roll call vote, voice vote, show of hands, etc.). Mek was felt to be much too anchored in the traditional meeting context to be accorded generic status, then qualified to express the different kinds of voting. It was therefore dropped, and in its place another pre-existing word, sọno (ratify/concur), was adopted as generic to which qualifiers could more easily be attached.

Another example of how a pre-existing term may be inappropriate (and perhaps dropped in a terminology resource) is implied in research findings by Askira (1994, reviewed in Antia 2000, 46 - 47). To confirm the motivational adequacy of terms used in several Nigerian languages for specific concepts, Askira has respondents rate several English backtranslations' of each local language term. The idea is to determine whether terms are strong candidates for standardisation: the back- translation or meaning that is selected by most respondents would be the one with the strongest candidacy status for standardisation as the meaning of the term.

For 'x-ray' back-translations include photography of the chest and something akin to (medical) photography. The former (a literal back-translation of the local language term) is selected by most respondents. This is clearly a case of mismatch between informed and uninformed understandings of ' $\mathrm{x}$-ray'. While misnomers are not uncommon in terminology, in a real rather than hypothetical standardisation scenario, a strong argument against this widely preferred meaning might have been the need to express x-rays of other body parts. The spectre of 'leg $x$-ray' becoming ' $x$-ray of the chest of the leg' would probably see a widely preferred term dropped. The models of knowledge change in child language acquisition and the philosophy of science provide a measure of legitimacy for motivated deletion or 
dropping of well known, ostensibly strong candidate-equivalents in the course of terminology development.

\subsection{Reorganisation in terminology development}

There is evidence that reorganisation of concepts or knowledge, amply illustrated earlier in the context of the philosophy of science, also occurs in terminology development. In a project where the Efik language is made to transition to a more sophisticated medium for expressing legislative concepts (associated with the US Congress and the British House of Commons), Antia (2000, 208 - 209) discusses reorganisation associated with the concept 'to vote'. As seen previously, the pre- existing Efik word for indicating preference at elections was ' $m e k$ ' - carried out by thumb-printing or by a show of hands. See Figure 5 .

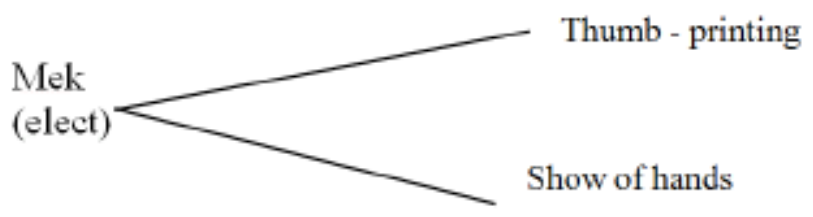

Figure 5: Traditional Efik conceptual system for voting (Antia 2000, 208)

An analysis of the manner in which Efik terminology is made to express concepts around indicating preference for positions reveals the following processes of knowledge reorganisation: dropping an existing word (mek), extending the meaning of an existing word (sônọ), adding qualifiers to the word whose meaning has been extended (to achieve appropriate differentiation). See Figure 6.

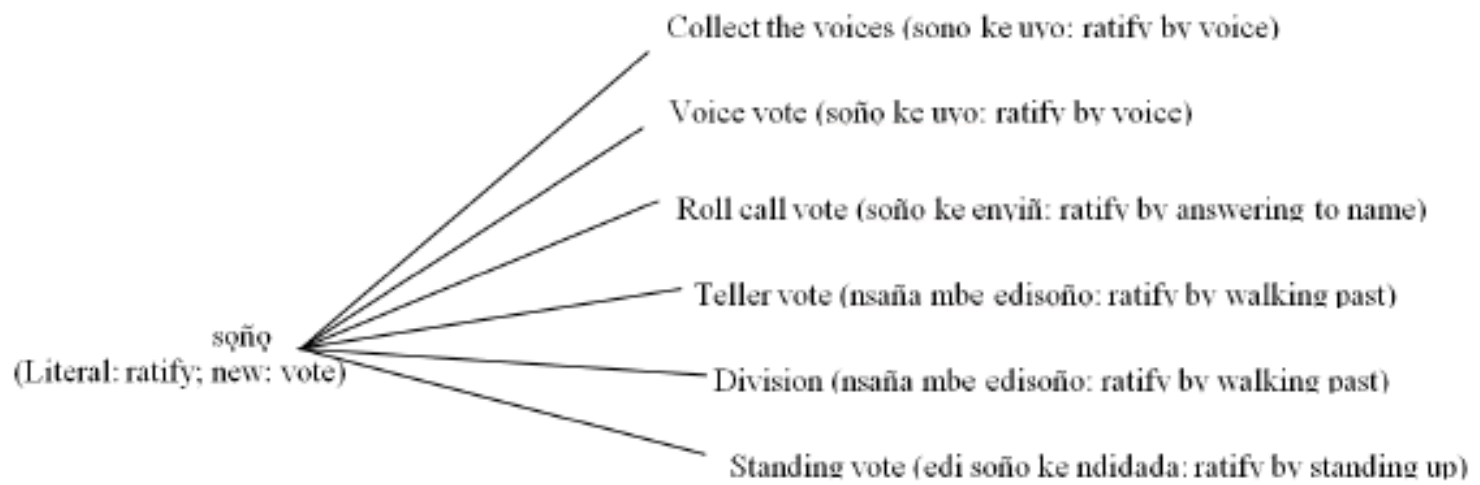

Figure 6: New conceptual system around voting in Efik (Antia 2000, 209)

In sum, we have seen that terminology development is not essentially an accretive process of adding previously non-existing forms to the vocabulary of a language. Consistently with processes in child language acquisition and the philosophy of science, the available evidence suggests that some of the needs and processes in terminology development are 
often related to issues of meaning relationships (e.g. redefinitions or semantic extension), deletions and restructuring of the conceptual space.

\section{Discussion and implications}

Of three major approaches to term formation identified by Sager (1990, 71; 1997, 28), namely, use of existing resources, modification of existing resources, and creation of new linguistic entities, the previous section shows that terminology development makes more use of the first two approaches. In other words, terminology development follows the model of knowledge change in child language acquisition and the philosophy of science in being less about accretion through totally new creations and more about the reuse and reconfiguration of existing material. In terminology, totally new creations are described as very rare (Arntz et al. 2014, 124; Sager 1997, 38).

These findings are also consistent with theoretical work on term formation within the terminologies of specific disciplines (e.g. satellite communications, documentation), illustrating how existing material is reused to grow terminology (Kageura 2002; NkwentiAzeh 1994). This work shows how, besides grammatical constraints, conceptual specification patterns (e.g. permissible intra-term relations) or conceptual characteristics of a specific discipline (or areas within a discipline) especially determine how: items in multi-unit terms are combined; what items in such multi-unit terms tend to occupy what positions (initial, medial, final); which items (e.g. nucleus or head, determinants or modifiers) tend to be more reused, and so on. Nkwenti-Azeh's analysis of the conceptual logic in satellite communications in English generates rules of what can be terms or nonterms. For example: Any sequence of lexical item $1+$ lexical item 2 is a candidate term if lexical item 1 has a positional value P1-2 (i.e. lexical items occurring as the first element of two- element compounds) and lexical item 2 has a positional value $\mathrm{P}_{3}-3$ (i.e. lexical items occurring as the third element of three-element compounds). From a positionally tagged corpus, this rule would generate (a) and (b) as acceptable candidate terms but not (c):

a) spectral[P1-2] components[ $\left[\mathrm{P}_{3}-3\right]$

b) baseband[P1-2] channels[ $\left.\mathrm{P}_{3}-3\right]$

c) operation[P3-3] status[P3-3] (Nkwenti-Azeh 1994, 77).

This line of investigation underscores how the logic in the conceptual space of a discipline works to allow for some measure of recursiveness in terminology development.

Although reassuring, given the frightening prospect of new, previously unattested lexical entities being invented for each and every new concept, the findings of this study suggest that the engagement in terminology development with sometimes abstruse specialised content area knowledge would have to be more than perfunctory. Clearly, the use and modification of existing resources (rather than a reliance on neologisms) imply some effort at relating the analysis of existing word meanings and semantic fields to the analysis 
of characteristics of specialised concepts (to be designated) and the disciplinary knowledge structure formed by the links existing among the concepts.

Methodologically, then, this calls for:

- Identifying relevant concepts (using terms as proxies) of a given domain, both as they are known to exist in a language whose range is to be functionally extended, and as documented in a reference language in which the domain is more fully developed. Recall from the botany project example that the former may not necessarily be a tabula rasa.

Developing the concept system of the given domain as attested in the two languages above. A concept system presents the relations among concepts, and it 'serves to: enable comparisons to be made of concepts and their terms in a language (e.g. in the analysis of synonyms) or between different languages (analysis of equivalents); to form the basis for unifying and standardising terminology; to order knowledge' (COTSOES 2002, 53).

- Modelling individual concepts within each concept system to facilitate comparisons across systems; that is, identifying a concept's characteristics via itemisation by using, for example, the slot and filler convention of frame representation. To model the concept of 'child benefit' in the context of state welfare programmes, possible [slots] and (fillers) would be: [goal]: (education of child); [source]: (government); [beneficiary]: (parent/guardian); etc. (Martin and Van der Vliet 2003, 346).

- Comparisons at the level of concept systems and at the level of individual concepts, in order to identify symmetries/asymmetries across both the language whose range is to be extended and the language where the disciplinary knowledge is more fully developed. Recall from the x-ray example that an existing term in the former language may not be appropriate when seen within the ontology of knowledge in the discipline (here: the different kinds of x-ray). These comparisons also serve to indicate potential courses of action to be taken on the vocabulary of the language being functionally extended: semantic extension of existing words, deletion or dropping of existing words, restructuring of relations holding concepts together, and so on.

- Ideally using information from the earlier stages to develop terms and to write coherent definitions that reflect the structure of the area of disciplinary knowledge the terminology resource seeks to address.

It is against the backdrop of such an exercise, especially engagement with disciplinary knowledge structures, that terminology development can more optimally respond to, or fully draw out, the implications of its substantially involving semantic extension, reorganisation, and so on. Sager (1997) underscores the relevance of modelling the target or disciplinary concept system when he writes that:

...the inherent knowledge structure of a subject field can suggest through its internal relations the preferred patterns for combining linguistic elements into terms. In an ideal situation, term formation obeys strict rules that mirror conceptual relations as far as the linguistic rule system permits. (Sager 1997, 26) 
Regrettably, in many terminology development projects, it rarely is the case that terms whether extracted manually or semi-automatically from running text - are graphically modelled and/or listed according to the relations obtaining among the underlying concepts. It typically is the case that terminology development is based on alphabetical lists, sometimes without definitions. Yet, the importance of modelling can be seen in the relative systematisation of designations for different voting types discussed earlier. It is this lack of attention to concept systems that leads Artnz, Amtz, Picht and Schmitz (2014) to the view which we cite in extenso below:

It is not uncommon to find terminological collections that are simply inventories of terms that are presented alphabetically. Without a clear-cut methodology, it is impossible to determine whether all the concepts in a subject field have been recorded. Furthermore, terms from outside the subject field are frequently included. In choosing terms to be used in the collection, the authors depend on their own experience, which means they proceed for the most part on the basis of intuition. Where definitions are available, they are often structured differently and violate formal rules for definitions. In addition, many collections that are produced in this manner attempt to cover as many subject fields as possible, and this leads to further inadequacies. The few exceptions that exist do not alter the overall negative picture. Under these conditions, we cannot speak of terminology management per se. (Arntz, Picht and Schmitz 14, 210; translated from the German by Sue Ellen Wright and Bassey Antia)

Fishman's endless laundry lists come to mind here. The need for engagement with domain knowledge and its broader ramifications clearly warrants various types of expertise in terminology development: linguistic expertise (for knowledge of word formation, orthography and other structural matters); cultural expertise (for etymological and other social-historical knowledge related to language); terminological expertise (for the nature of specialised communication and methodological issues); and subject field expertise (for the actual disciplinary content).

While there has recently been significant progress in acknowledging subject field expertise, in addition to the more established linguistic and cultural forms of expertise, there is reason to suspect (as the quotation from Arntz, Picht and Schmitz 2014 above shows) that terminological expertise, the bridge between the preceding cultural-linguistic forms of expertise and subject expertise, is insufficiently acknowledged. For instance, in terminology projects made up of mixed expertise teams, subject specialists may tend to violate the Gricean maxim of quantity, either in the attention to disciplinary minutiae or in assumptions made concerning the sophistication of a target audience's knowledge of disciplinary facts. Cultural and language experts may insist on the appropriateness of words belonging to a bygone era that have fallen out of currency, or on issues of acceptability (frequently determined by comprehensibility). 
It behooves the terminologist, leveraging on expertise in unlocking the ontology of knowledge in a domain and a unique understanding of specialised communication, to attempt to reconcile rival positions. Taking cognisance of the structure of concepts in the subject field, the terminologist would demonstrate why an existing designation in the language needs to be dropped because of concerns of usability around collocations and other co-texts; or why a new term needs to be motivated in a certain way; or why definitions should be authored (rather than translated from a source) to reflect the relevant concept system; or why a text authored on the basis of developed terminology cannot readily be understood by everyone who knows the relevant language but not the subject matter (after all not everyone with a knowledge of English understands an English text on sub-atomic physics). It is a terminologist's insistence on respecting this concept system that may resolve a problem of incompatible definitions offered by subject experts in a development team who come from different but related disciplines. Thus, the chemist's definition of water ('combination of two hydrogen atoms with one oxygen atom') may not necessarily be appropriate in a terminology on physics where water might be better defined as liquid with a freezing point of $0^{\circ} \mathrm{C}$ and a boiling point of $100^{\circ} \mathrm{C}$ at a pressure of 1 atm' (COTSOES 2002, 29-30).

Based on various organisational/expertise models employed in projects of the Finnish Terminology Centre, Nykänen (1993) presents data comparing, admittedly, only subjectfield expertise and terminological expertise. The finding is that terminologist-led collaborative teams produce better results than subject specialist-centered teams (see Table 2).

Table 2: Effects of various organisational and expertise models in terminology development

\begin{tabular}{|l|l|l|}
\hline & $\begin{array}{l}\text { Subject-specialist } \\
\text { centred models }\end{array}$ & $\begin{array}{l}\text { Terminologist- } \\
\text { centred models }\end{array}$ \\
\hline Concepts per month & 6 & 11 \\
\hline Meetings per 100 concepts & 16 & 6 \\
\hline Total cost per concept (in Finnish Marks) & 2300 & 1200 \\
\hline Terminologists' work per concept (in hours) & 5 & 3.4 \\
\hline Specialists' work per concept (in hours) & 4.5 & 1.3 \\
\hline Terminologists' proportion of total work & $50 \%$ & $70 \%$ \\
\hline
\end{tabular}

If work on terminology had merely been an accretive process of adding neologisms to a language's semantic field, it would be unlikely that, among other indicators, the total cost per concept in (then) Finnish marks would have been as high as reflected in Table 2. Clearly, responding to the dynamics of knowledge change as described in this article, and especially to the methodological correlates of knowledge change in terminology development, is a 
painstaking process which is, however, facilitated by a central role for terminological expertise.

Besides implications around the two related issues of methodology and expertise types, the analysis in this article also provides a canvas for thinking about how to obtain buy-in for terminology products. Criticisms of developed terms are often quite scathing, couched in personal preferences of the critic, hardly informed by knowledge structural constraints on decision-making (Antia and Clas 2003, $50-51$ ). In the discourse on terminology resources, the paucity of strands related to knowledge structure creates the discourse environment for criticisms that may sometimes come across as uninformed and unfair. As has been seen in previous sections, possible expectations around what words should be maintained, with what meanings, and so on, may be disappointed - only because of concerns related to the structure of knowledge. It is therefore important to explain such knowledge structureinformed decisions in the introductions, prefaces or other notes to terminology resources.

Finally, the analysis invites a consideration of the relationship between terminology and translation. One issue here relates to expressions such as 'translating terminology', 'translation strategy' or 'translation equivalents' that are commonly employed in describing terminology development. Such usage has the effect of subsuming one professional identity (terminologist) under another (translator); no less importantly, this usage raises questions regarding epistemological commitments. To be clear, the issue is not whether translators can create terminology; it is rather about determining whether the process of developing terminology can be called translation.

Without disregarding the important knowledge base underpinning translating, to speak of translating terms is to foreground concern with equivalence at a unit/ text level rather than at a system level. Although there is a dynamic interaction of both levels (Antia 2002, Kageura 2002), a text or parole focus on terms necessarily imposes single (at best successive) perspectives on the inherently multidimensional nature of terminological concepts (Bowker 1997; Gerzymisch-Arbogast 1996). Such a focus implies that much of the work around concept analysis that informs a system level focus is easily lost in text/translation contexts. This leads, paradoxically, to opinions about terms being 'inadequate' on back-translation, or to multiple term variants in the work of translators. Software-aided analyses of terminology in parallel texts (original language and translation) frequently show one source language term having multiple target language equivalents.

A second, related issue has to do with the status of terms introduced into a language through the translation of texts. While such terms are frequently useful, they often need to be processed and systematised further. Such processing might have the goal of determining which of several translation variants of a given term can be justified in disciplinary terms as opposed to representing a one-off solution in a particular text. It certainly cannot be taken for granted that translators necessarily have the time nor the expertise to research terminology when their immediate purpose is to mediate situated meaning. 
Wright and Wright (1997) highlight the methodological constraints that set terminology developed in translation contexts apart from the more systematic terminology activity. They refer to the kind of terminology developed in a translation environment as ad hoc terminology management. This need not be seen as a negative description. They note that terminologists working in the systematic terminology management context (subject-fielddriven terminology) 'have the time to collect materials, selecting terminology, and organising it according to logical concept systems' (Wright and Wright 1997, 148). This latter approach requires more than cursory engagement with knowledge structures. Systematic terminology development, as Wright and Wright note, 'affords the opportunity to work with experts and to craft careful definitions'.

\section{Conclusion}

In ideal cases, a set of terms developed in a language points to a profoundly knowledge-intensive activity within a given domain. Terminology development in the language planning context shares something in common with the processes of child language development and scientific knowledge (r) evolution. In all three cases, knowledge change is indexed lexico-semantically. The specific processes that have been identified in all three fields - addition, deletion, redefinition, reorganisation - encourage an exploration of further symmetries, for instance, with knowledge change in learning content subjects.

The evidence provided in this article makes a number of points. Firstly, it reiterates a fundamental point about the capacity of natural languages to respond creatively (using internal resources) to demands of novel expression made on them. In other words, extending the functional range (terminologically) of a language is much less about neologisms; it is rather much more about the reinterpretation of existing forms. The challenge, of course, is the availability of all relevant kinds of expertise required to put the resources of natural languages to work. Secondly, the article makes the point that knowledge change, such as inevitably occurs when terminology is developed, involves accommodating the old and the new. In elaborating a subject- field terminology in an African language, previously existing terms clearly need to be taken into account; but by the same token, it has to be understood (as with the x-ray example) that there may be knowledge ontological considerations that may explain why existing terms cannot be used in the terminology. 


\section{References}

Allot, R. 2005. The child and the world: How the child acquires language, how language mirrors the world. Hertfordshire: Able.

Ambridge, B. and A.V.M. Lieren. 2011. Child language acquisition: Contrasting theoretical approaches. Cambridge: Cambridge University Press.

Antia, B.E. 2000. Terminology and language planning: An alternative framework of practice and discourse. Amsterdam: John Benjamins.

Antia, B.E. 2002. II termine - contesto definitorio e contesto d'uso [The term: context of definition and context of use]. In Manuale di terminologia. Aspetti teorici, metodologici e applicative, ed. M. Magris, M.T. Musacchio, L. Rega and F. Scarpa, 99-114. Milan: Hoepli.

Antia, B.E. and A. Clas. 2003. Terminology evaluation. In Terminology in advanced management applications, ed. G.M. de Schryver, 45-52. Pretoria: SF Press.

Arntz, R., H. Picht and K.D. Schmitz. 2014. Einführung in die Terminologiearbeit [Introduction to terminology]. 7 th edition. Hildesheim: Olms.

Atkinson, M. 1982. Explanations in the study of child language development. Cambridge: Cambridge University Press.

Bamgbose, A. 2000. Language and exclusion: The consequences of language policies in Africa. Hamburg: LIT.

Blom, E. and S. Unsworth. 2010. Experimental methods in language acquisition research. Amsterdam/Philadelphia: John Benjamins.

Bloom, L. 1993. The transition from infancy to language: Acquiring the power of expression. New York: Cambridge University Press.

Boysson-Buddies, B. 2001. How language comes to children. Cambridge: MIT Press.

Bowker, L. 2007. Multidimensional classification of concepts and terms. In Handbook of terminology management: Basic aspects of terminology, vol. 1, comp. S.E. Wright and G. Budin, 133-143. Amsterdam: John Benjamins.

Budin, G. 1996. Evolution of scientific terminologies. In TKE '96: Terminology and knowledge engineering, ed. C. Galinski and K.D. Schmitz, 27-34. Frankfurt: Indeks.

COTSOES 2002. Recommendations for terminology work. Berne: Media Centre of the Confederation.

Crystal, D. 1987. Child language learning and linguistics. London: Edward Arnold.

Devescovi, A., M.C. Casselli, D. Morchione, P. Pasqualetti, J. Relly and E. Bates. 2005. A crosslinguistic study of the relationship between grammar and lexical development. Journal of Child Language (32): 758-786.

Dromi, E. 1996. Early lexical development. San Diego: Singular Publishing Group.

Fishman, J.A. 1983. Modelling rationales in corpus planning: Modernity and tradition in images of the good corpus. In Progress in language planning, ed. J. Cobarrubias and J.A. Fishman, 107 - 118. Berlin: Mouton.

Foucault, M. 1972. Archaeology of knowledge and the discourse of language. New York: Pantheon Books.

Gauton, G., E. Taljard and G.M. de Schryver. 2003. Towards strategies for translating terminology into all South African languages: A corpus-based approach. In 
Terminology in advanced management applications, ed. G.M. de Schryver, $81-88$. Pretoria: SF Press.

Gerzymisch-Arbogast, H. 1996. Termini im Kontext. Verfahren zur Erschließung und Übersetzung der textspezifischen Bedeutung von fachlichen Ausdrücken [Terms in context: Processes for identifying and translating text-specific meanings of specialised expressions]. Tübingen: Gunter Narr.

Haugen, E. 1966. Linguistics and language planning. In Sociolinguistics: Proceedings of UCLA sociolinguistics conference, 1964, ed. W. Bright, 50-71. The Hague: Mouton and Co.

Hornberger, N.H. 2006. Frameworks and models in language policy and planning. In An introduction to language policy: Theory and method, ed. T. Ricento, $24-41$. Oxford: Blackwell.

Kageura, K. 2002. The dynamics of terminology: A descriptive theory of term formation and terminological growth. Amsterdam/Philadelphia: John Benjamins.

Kühn, P. 1989. Typologie der Wörterbücher nach Benutzungsmöglichkeiten [A typology of dictionaries according to situations of use]. In Wörterbücher: Ein internationales Handbuch zur Lexikographie, vol. 1, ed. F.J. Hausmann, O. Reichmann, H.E. Wiegand and L. Zgusta, 111 - 127. Berlin and New York: Walter de Gruyter.

Kuhn, T.S. 1996. The structure of scientific revolutions ( $3^{\text {rd }}$ edition). Chicago/London: University of Chicago Press.

Lenneberg, E.H. 1967. Biological foundations of language. New York: Wiley.

Lust, B. 2006. Child language acquisition and growth. Cambridge: Cambridge University Press.

Mabasa, T.A. 2006. Translation equivalents for health/medical terminology. MA dissertation submitted to the University of Pretoria.

Maiga, A. 1991. La place de la terminologie dans l'alphabétisation fonctionnelle [The role of terminology in functional literacy programmes]. Terminologies Nouvelles (9): 3236.

Martin, W. and H. van der Vliet. 2003. Design and production of terminological dictionaries. In A practical guide to lexicography, ed. P. van Sterkenburg, 333 - 349. Amsterdam/Philadelphia: John Benjamins.

Montgomery, M. 2008. An introduction to language and society. (3rd edition). London: Routledge.

Nkwenti-Azeh, B. 1994. Positional and combinational characteristics of terms: Consequences for corpus-based terminography. Terminology 1(1): 61-95.

Nykänen, O. 1993. Cost analysis of terminology projects. TermNet News (42/43): 20-23.

Oates, J. and A. Grayson. 2004. Cognitive and language development in children. United Kingdom: Open University Press.

Pinker, S. 1994. Language learnability and language development. Cambridge: MIT Press. Reich, P.A. 1986. Language development. New Jersey: Prentice-Hall.

Sager, J.C. 1990. A practical course in terminology processing. Amsterdam/Philadelphia: John Benjamins. 
Sager, J.C. 1997. Term formation. In Handbook of terminology management: Basic aspects of terminology, vol. 1, comp. S.E. Wright and G. Budin, 25 - 41. Amsterdam: John Benjamins.

Sonaiya, R. 1991. Vocabulary acquisition as a process of continuous lexical disambiguation. International Review of Applied Linguistics in Language Teaching 29(4): $273-284$.

Saxton, M. 2010. Child language acquisition and development. London/New Delhi: Sage. Thagard, P. 1992. Conceptual revolutions. Princeton: Princeton University Press.

The New Webster's Dictionary of the English language. 1995. New York: Lexicon Publications.

Vygotsky, L.V. 1962. Thought and language. Cambridge: MIT Press.

Webb, V. 2004. African languages as media of education: Stating the case. Language Problems and Language Planning 28(2): 147 - 173.

Wright, S.E. and L.D. Wright. 1997. Terminology management for technical translation. In Handbook of terminology management: Basic aspects of terminology, vol. 1, comp. S.E.

Wright and G. Budin, 147 - 159. Amsterdam: John Benjamins. 